chromatographic behaviour of a liquid-phase sequence such as dibutyl-, diethyl- and dimethyl-formamides. Deviations from a general liquid phase 'polarity order', for example:

paraffin < dinonyl phthalate < dibutyl phthalate < tricresyl phosphate < methoxy polyethylene glycol

$350<1,2,3$-trans (2-cyano ethoxy propane)

could in some cases be ascribed to solute-solvent hydrogen bonding, but there appeared to be no indications of specific aromatic-aromatic interactions.

Dr. J. F. Smith (Natural Rubber Producers' Research Association, Welwyn Garden City) put the case for presenting retentions relative to the $n$-alkanes; either his own $R_{x_{9}}$ (relative to $n$-nonane) or the retention index system of Kovats was suitable. The relative merits of bracketing the compound to be characterized with $n$-alkanes in one run, or determining the retention of the compound either on its own, or with one $n$-alkane, or bracketed with two $n$-alkanes and then comparing with a separate run of four $n$-alkanes were discussed as was the use of non-linear log-plots when retentions were measured from the point of injection instead of the air-peak. For detectors not responding to air, methane could be used to give the hold-up if the column temperature were greater than $70^{\circ}$ C. Dr. P. A. T. Swoboda presented evidence that the same retention index values were obtained by interpolation from retentions measured from the point of injection as were obtained from retentions measured from the air peak. With the former procedure, however, as Dr. Smith had mentioned, the slope of the log-plots had to be determined from the asymptote. Published $V g$ values for alkyl nitroand nitrate compounds (Evered and Pollard, Journal of Chromatography, 4, 451; 1960) were used by Dr. Swoboda to illustrate an example of the temperature independence of values of retention index. A written contribution by $\mathbf{H}$. van den Dool and P. de C. Kratz showed that there was good agreement between values of retention index obtained under isothermal and temperature programmed conditions.

Mr. B. A. Knights suggested that in steroid chemistry the gas-liquid analogue (Nature, 194, 833; 1962) of the $R_{M}$ value $\left[\log \cdot\left(\frac{1}{R_{F}}-1\right)\right]$ of liquid-liquid systems which could be broken down into contributions from the parent molecule and functional groups should be used to keep the nomenclature in this field as uniform as possible.

In summary, it would appear from the papers and discussion during the afternoon session that once a liquid phase has been characterized in terms of the slope of the log-plot for $n$-alkanes at several temperatures, workers need only report their results relative to one or more $n$-alkanes and the devotees to each system would soon provide a wealth of derived data.

C. G. ScotT

\title{
COASTAL PROCESSES
}

A SEMINAR on "Coastal Processes" was held at the Department of Geography, University of Cambridge, during June 29-30. Thirty scientists attended the seminar, including geographers, oceanographers, engineers and geologists, most of whom were from the United Kingdom. Those attending from overseas were four engineers from the Dutch Rijkswaterstaat, including J. B. Schijf, director of research, Prof. A. J. Guilcher of Paris and three Australian engineers. Prof. J. A. Steers of Cambridge acted as chairman for the five sessions into which the discussions were divided, namely : $(a)$ wave generation as it affects sediment movement; $(b)$ beach processes, in the surf zone and beyond; $(c)$ beach cycles, annual and long term; $(d)$ equilibrium shapes of coastline in plan ; (e) world-wide sediment movement.

Wave generation. For the purposes of studying movement of sediments it was pointed out that only two categories, storm waves and swell, need be considered. The former are still within the fetch while the latter have moved outside it and travel in everenlarging circles across the oceans of the world. Waves are seen to be an efficient means of spreading the energy of the wind in given storm areas over the surface of the Earth. Seas, partially or fully enclosed, experience less swell action than coasts bordering the major oceans and, therefore, the beach profiles are significantly different.

Beach processes. The breaking of waves on the beach creates two distinct zones in which sediment is transported: the surf zone and the offshore area beyond the breaker line. Although great turbulence and high velocities exist in the surf zone, more sediment can be transported in the offshore area because of the greater width of action. This width can be miles in some cases, out to depths of 40 fathoms for 10-sec waves and 100 fathoms for 15 -sec waves. The difficulties of verifying the theory on this movement were outlined by many speakers.

The action of swell accreting a beach was discussed with emphasis placed on the mass transport ${ }^{1}$ of the waves in moving the sediment towards the shore. It was noted how the ripple formation on the sea-bed changes with variations in wave height, period and direction-this disturbed state producing larger rates of sediment transport. The action of storm waves on the steep swell beach profile was seen to be a combination of a hydraulic jump from the backwash occurring at a point on the beach face where the sand is in quasi-suspension due to the excessive ground-water returning to the sea at this point $t^{2,3}$. However, after the material has been forced into an offshore bar the erosion ceases since waves are then dissipated on the bar.

Beach cycles. Storm waves, due to their short duration, are not significant in moving sediment along the coast. Swell, on the other hand, being produced consistently from wind systems, which are repetitive year in and year out, moves material in one particular direction when returning it from the offshore bar to the beach. Any interference with the longshore drift can result in erosion of the offshore area, which then requires more sediment during the next storm sequence before the bar is sufficiently high to protect the beach. Thus, storm waves display the previous erosive action of the swell.

Although most of the discussion related to wave action at a constant sea-level it was noted how tidal fluctuations spread the energy of waves over a greater width of beach profile. The combined action of $(a)$ tidal streams, (b) the salt water wedge and (c) wave propagation into an estuary, causes continuous siltation. 
Coastlines in plan. The arrival of the most persistent swell from a specific direction causes a net movement of sediment along the shore. It is important to know its direction in the design of maritime structures. A model study of the action of oblique swell on a straight sedimentary coastline with headlands, reported elsewhere ${ }^{4}$, indicated that half-hoartshaped bays were formed. The depth of indentation depends on the supply of material from upcoast, but for a condition of complete non-replenishment an equilibrium is reached for any given wave direction, in which event sediment movement ceases altogether. Examples from actual coastlines were cited in which a predominant swell direction was known to exist and where the bay formation was well developed.

The most efficacious location of groynes within such bays was diseussed. The uso of artificial headlands to stabilize coastal transport by promoting bay formation was submitted as a better solution than groynes, which in general influence only sand within the surf zone and are subject to rip formation.

Coastlines of the world. The half-heart shape of bay can be used as a tool to determine the direction of sediment movement on any coastline. This has been done by examination of Admiralty charts covering all oceans of the world and is reported elsewhere ${ }^{5}$. Where the equilibrium shape is not available other factors such as sand spits behind islands, as reported by Prof. Guilcher, ean be used. The final world-wide pattern of sedimont movement so obtained has correlated well with the wind systems of the globe. The work of J. L. Devies on similar lines ${ }^{6}$ was reported.

The meeting was convened in order to bring together research workers from various fields who wero interested in the particular study of sedimentary coastlines. It also served the purpose of indicating the different conditions experienced on coasts open to the ocean swell and thoso where the majority of the waves are generated locally. Emphasis was placed on wave action in the transport of material as distinct from tidal or other currents, which are of minor importance unless they are concentrated in narrow or shallow channels. R. SILvester

${ }^{1}$ Lonquet-Higgins, M. 8., Phil. Trans. Roy. Soc. (Lond.), A245, No. 903, 535 (1953).

2 Emery, K. O., and Foster, J. F., J. Mar. Res., "7, 644 (1948).

3 Grant, U. S., J. Mar. lies., 7, 655 (1948).

4 Silvester, R., Nature, 188, 467 (1960)

- Silvester, R., Proc. Conf. Inst. Civil Engin. Paper No. 14 (1962).

- Davies, J. I.., Z. Geomorphol. (in the press).

\section{COMPARATIVE ENDOCRINOLOGY IN EUROPE}

A CONFERENCE of European Comparative Endocrinologists was held in London in the rooms of the Zoological Society, by courtosy of the Council of the Society, during Septomber 19-21, and was attended by about 100 representatives of twelve countries. It was opened by Prof. G. J. van Oordt, who had been invited, on the occasion of his retirement from his chair of gonoral zoology and endocrinology in the University of Utrecht, to review aspects of European comparative endocrinology with which he and his colleagues had been closely connected.

Ho chose to deal particularly with developments in the field of sexual endocrinology, a subject which he introduced forty years ago into the biological laboratories of the Netherlands. The far-reaching influence that he has exerted through his own investigations, as well as through those of his pupils, was clearly brought out by the varioty of topics on which ho was able to touch, the major ones including the control of the reproductive processos of fishes and birds, and the factors influencing spermiation in amphibians. In declaring the Conference open, he expressed his confidence in the bright future of comparative endocrinological studies in Furope, and this optimism was cortainly justified by the interest and variety of the forty-eight papers which made up the rest of the scientific programme. It must be sufficient here to mention the main trends that emerged, for his addross will be published in full, together with abstracts of the other communications, in the current volume of General and Comparative Endocrinology.

A welcome feature was the prominence of invertebrate endocrinology, which was the subject of fourteen of the papers, for thero is sometimes a tendency for such conferences to concentrate on the higher vertebrates, and thereby to lose the great advantage of observing the working out of common principles in widely different groups of the animal kingdom. Studies of insects were naturally conspicuous here, and the widening range of application of ondocrino- logical principles was seon in an account of the role of sex ectohormones (pheromones) in the termite superorganism, the analysis of which can be pursued by methods fully analogous with those used in endocrine studies within the bodies of individual animals.

The control of colour change in crustaceans and the growth and moulting of both insects and crustaceans were discussed by several speakers, and it was gratifying to find that the endocrinological basis of these latter processes is now being studied in the difficult but important group of mites. The increasing attention that is being attracted by the lower invortebrates was also apparent, for several papers dealt with the annelid worms, with particular reference to the influence of neurosecretory centres on their reproduc. tion and life-cycles, including the induction and inhibition of the heteronereid phase.

The pituitary gland inevitably predominated in several sessions, in one or other of its many functional aspects. Prof. van Oordt's address was followed by several papers dealing with the control of colour change in Amphibia, and the younger workers present may well have been encouragod to find how vigor. ously rosearch and controversy are still being maintained in a subject that has for so long been a classical field of comparative vertobrate endocrinology. The pars distalis and its hormones also received attention, and papers on both electron microscopy and the more traditional polychromatic staining methods showed that while the complexity of this region is in full accord with the known variety of its functions, wo are still in no position to systematize our knowlodge of its histological differentiation.

The neurohypophysial hormones were dealt with by a numbor of workers, and rightly so, for in fow fields has the application of the comparative method yielded more stimulating results in recent years. Problems of the phyletic distribution of these hormones and of their modes of action were prominent. 